\title{
CD-56 IMMUNOREACTIVITY IN FOLLICULAR CELL DERIVED LESIONS OF THYROID
}

\author{
Elvin Merin Cherian'1, Priya P. V2, S. Sankar ${ }^{3}$
}

1 Postgraduate Student, Department of Pathology, Government Medical College, Kottayam, Kerala.

${ }^{2}$ Associate Professor (CAP), Department of Pathology, Government Medical College, Kottayam, Kerala.

3 Professor and HOD, Department of Pathology, Government Medical College, Kottayam, Kerala.

\section{BACKGROUND}

ABSTRACT

The microscopic distinction between benign and malignant lesions by conventional histology is at times difficult. Diagnosis of papillary carcinoma is based on specific nuclear features however, focal presence of the same features in other follicular epithelial lesions make the distinction of papillary carcinoma thyroid from other lesions difficult. Morphologic overlap between follicular lesions especially the follicular variant of papillary carcinoma and FC is quite common. Cellular nodules may exhibit similar nuclear features like that of papillary carcinoma thyroid due to defects in processing, in which case, distinction between the two becomes difficult. Follicular thyroid lesions have in common many morphological features, which frankly put a burden on the pathologist while trying to make a diagnosis by H\&E. The objective of this study is to evaluate the expression of CD56 in follicular cell derived lesions of thyroid.

\section{MATERIALS AND METHODS}

This is a descriptive study conducted on the thyroid specimens received in the Department of Pathology, Government Medical College, Kottayam with a histological diagnosis indicating follicular cell derived lesion during a period of 18 months (May 2016October 2017).

\section{RESULTS}

Among the 40 cases in the study group, 9 cases were non-neoplastic; all of which were cellular nodules (22.5\%). Of the 31 cases of thyroid neoplasms, 25 cases were Papillary carcinoma thyroid and its variants which included 4 cases of papillary microcarcinoma $(10 \%), 6$ cases $(15 \%)$ were follicular variant and 1 case $(2.5 \%)$ of diffuse sclerosing variant. Six cases were Follicular carcinoma (15\%). CD56 showed a positive expression in $88.88 \%$ cases of non-neoplastic lesions, a negative expression in $96 \%$ cases of Papillary carcinoma and its variants and a positive expression in $66.66 \%$ cases of follicular carcinoma.

\section{CONCLUSION}

Based on the findings of the present study, CD56 may be considered as a relevant marker of papillary carcinoma-thyroid and its variants and is useful in distinguishing papillary carcinoma-thyroid and hyperplasia/follicular carcinoma

\section{KEYWORDS}

Hyperplasia; Thyroid Neoplasms; Papillary Carcinoma Thyroid; Immunohistochemistry.

HOW TO CITE THIS ARTICLE: Cherian EM, Priya PV, Sankar S. CD-56 immunoreactivity in follicular cell derived lesions of thyroid. J. Evolution Med. Dent. Sci. 2018;7(17):2066-2073, DOI: 10.14260/jemds/2018/464

\section{BACKGROUND}

Thyroid nodules are extremely common in the general population with the estimated prevalence ranging from 19 to $35 \%$ and are usually detected during routine medical care. It is estimated that up to $7 \%$ of the general population develops clinically palpable thyroid nodules. However, increase in thyroid cancer incidence has been reported in the last 30 years by different studies. Although tumours of the thyroid account for only $1 \%$ of the overall cancer burden, they represent the most common malignancies of the endocrine system.

In India 42 million people suffer from thyroid diseases. Thyroid cancer is reported to be most prevalent in the coastal areas of Kerala and Karnataka. As per the national cancer

'Financial or Other Competing Interest': None.

Submission 19-01-2018, Peer Review 05-04-2018,

Acceptance 12-04-2018, Published 23-04-2018.

Corresponding Author:

Dr. Priya P. V,

Department of Pathology, Government Medical College,

Kottyam-686008, Kerala.

E-mail: drpvpriya@yahoo.com

DOI: $10.14260 /$ jemds $/ 2018 / 464$ registry 3-year report 2009-2011, the relative frequency of thyroid cancer among all the cancer cases was $0.1-0.2 \%$ of which Thiruvananthapuram and Kollam had the highest number of registered cases of thyroid cancer.

Patients with differentiated thyroid carcinoma have an excellent 10-year survival ranging between 80 and 95\%. This is because the natural course of the disease is relatively mild and treatment of this tumour type, which consists of thyroidectomy followed by high-dose radioiodine and lifelong thyroid hormone therapy, is highly successful. Appropriate treatment then rests on the ability of the pathologist to give an accurate diagnosis. Tissue biopsy and routine H\&E staining are the gold standard in the diagnosis of thyroid nodules. The microscopic distinction between benign and malignant lesions by conventional histology is at times difficult. Most of the discovered nodules are benign. More than $80 \%$ of the malignancies present in palpable thyroid nodules are papillary thyroid carcinoma followed by follicular carcinoma Diagnosis of papillary carcinoma is based on specific nuclear features. However, focal presence of the same features in other follicular epithelial lesions make the distinction of papillary carcinoma thyroid from other lesions difficult 
Morphologic overlap between follicular lesions especially the follicular variant of papillary carcinoma (FVPTC) and Follicular carcinoma (FC) is quite common. The final diagnosis is then determined by evaluation of the specific characteristics of FC such as vascular and capsular invasion. FVPTC is characterized by an almost exclusive follicular growth pattern and a set of nuclear features identical to those of the conventional type of papillary carcinoma thyroid (PTC). Diagnostic dilemma also arises when an encapsulated nodule with a follicular pattern of growth exhibits clear nuclei with grooves and hence distinguishing follicular adenoma from encapsulated FVPTC becomes difficult. Multinodular goiter with delicate papillary branching and focal nuclear clearing may often be confused with PTC. Papillae formation can occur focally in follicular adenoma as well. In such cases diagnosis based on morphologic assessment alone is very difficult. Similarly, cellular nodules may exhibit similar nuclear features like that of papillary carcinoma thyroid due to defects in processing in which case distinction between the two becomes difficult. Follicular thyroid lesions have in common many morphological features, which frankly put a burden on the pathologist while trying to make a diagnosis by H\&E slides. Even amongst experienced pathologist there usually exists inter-observer variability. Furthermore, intra-observer variability is seen when they review the same H\&E slides after some period of time.

In an attempt to solve this diagnostic dilemma immunohistochemistry has been proven to be useful. Some markers like CK19, CD56, GALECTIN-3, CD44 have been studied. CD56 is a newly reported, "promising" marker in thyroid pathology, but, to present date, literature data is few and inconsistent. This study is to be conducted to investigate the role of CD56 as a possible diagnostic marker in thyroid lesions.

\section{MATERIALS AND METHODS}

Type of Study

Descriptive observational study.

\section{Study Period}

18 months (May 2016 - October 2017).

\section{Study Setting}

Department of Pathology, Govt. Medical College, Kottayam.

\section{Sample Size}

40.

\section{Study Tools}

1. Instruments to take bits of tissues to be studied.

2. Reagents for tissue processing.

3. Instruments for making paraffin blocks and cutting thin sections from it.

4. Glass slides and cover slips for mounting.

5. Binocular research microscope.

6. Eosin- Haematoxylin staining.

7. Mouse monoclonal CD56 antibody and other reagents for immunohistochemical studies.

8. Proforma to record serial number, Biopsy number, Name, age, sex, FNAC results, gross, histopathology and immunohistochemical features.

\section{Study Procedure}

Clinical details of each case were recorded first along with radiological and cytological results. Gross examination of the specimen was done. Tumour size was measured in three dimension and the largest dimension was taken into account. Appropriate bits of tissues representative of areas to be studied taken. All specimens were fixed in formalin and embedded in paraffin. 4 microns thick sections were stained with $\mathrm{H} \& \mathrm{E}$ for routine histological examination. Immunohistochemical staining was performed using mouse monoclonal CD56 antibody. Immunoreactivity is assessed according to the distribution of staining. Positive control: normal colloid filled thyroid tissue. Negative control: omit primary antibody. CD 56 gives membrane positivity with or without cytoplasmic positivity in all follicular cell derived lesions of thyroid except PTC and its variants. A semiquantitative assessment of immunohistochemical scoring was performed. Immunoreactivity was considered positive if more than $10 \%$ of the follicular epithelial cells were stained. Immunoreactivity was scored as 0 when stained in less than $10 \%$ tumour cells, score 1 when tumour cells stained between $10-25 \%$, score 2 when stained in 26 $50 \%$ and score 4 when stained in more than $50 \%$ tumour cells. A score of 0 was considered negative and a score of 1-3 was considered positive.

\section{Data Management and Analysis}

The data was entered in Microsoft excel and further statistical analysis was done using SPSS software.

\section{Inclusion Criteria}

Histopathologically diagnosed cases of all follicular cell derived lesions of thyroid during the study period were included.

\section{Exclusion Criteria}

Cases without proper data, cases with differential diagnosis, recurrent/treated cases of papillary carcinoma thyroid were excluded.

\section{RESULTS}

The present study was conducted on 40 thyroid specimens received in the department of Pathology, Government Medical College, Kottayam during the study period of 18 months with a histological diagnosis indicating a follicular cell derived lesion.

\section{Age Distribution of Study Population}

The youngest patient in the study group was 20 years of age and the oldest patient was 84 years of age. The mean age of the study group was $47.25 \pm 16.04$ years. 17 cases $(42.5 \%)$ belonged to the age group of $41-60$ years, 14 cases (35\%) belonged to the age group of 21-40 years, 8 cases $(20 \%)$ were more than 60 years and one case $(2.5 \%)$ belonged to the age group of 0-20 years.

\section{Gender Distribution of Study Population}

The study group consisted of 30 females (75 \%) and 10 males (25\%) with female to male ratio of $3: 1$ 
Frequency of Non-Neoplastic and Neoplastic Lesions among Study Group

Among the study group 31 were neoplastic and 9 cases were non-neoplastic

Frequency of Neoplastic and Non-Neoplastic Lesions in various Age Groups

Among the 31 cases of neoplastic lesions, 14 cases (35\%) were seen in the age group between 41-60 years, 11 cases $(27.5 \%)$ were seen in the age group of $21-40$ years and 5 cases $(12.5 \%)$ in more than 60 years of age. 3 cases of nonneoplastic lesions $(7.5 \%)$ were seen each in the age groups of 21-40 years, 41-60 years and more than 60 years.

\section{Frequency of Thyroid Lesions among Study Group}

14 cases (35\%) were of classical PTC, 4 cases $(10 \%)$ of papillary microcarcinoma, 6 cases $(15 \%)$ of FVPTC, 1 case $(2.5 \%)$ of diffuse sclerosing variant of PTC, 5 cases $(12.5 \%)$ of FC-MI, one case $(2.5 \%)$ of FC-WI and 9 cases $(22.5 \%)$ of cellular nodule.

\section{Frequency of PTC Lesions and Non-PTC Lesions in Study} Group

25(62.5\%) cases among the study group were PTC and 15 Cases (38\%) were NON-PTC

\section{CD56 Expression in the Study Group}

Twenty-six cases $(65 \%)$ showed a score of 0 , two cases $(5 \%)$ showed a score of 1 , two cases $(5 \%)$ showed a score of 2 and ten cases showed a score of $3(25 \%)$

\section{Frequencies of CD56 Expression in Neoplastic and Non-} Neoplastic Lesions

Among the 9 non-neoplastic lesions of thyroid 8 cases (88.8\%) showed positive expression of CD56 with a score of 3 and one case showed a score of $2(11.11 \%)$

of the 31 cases of neoplastic lesions of thyroid in the study group, twenty-six cases $(83.87 \%)$ showed a negative expression of CD56 with score 0 , two cases (6.45\%) showed a score of 1 , one case (3.22\%) showed a score of 2 and two cases $(6.45 \%)$ showed a score of 3 . The expression of CD56 among the neoplastic lesions in the study group were found to be statistically significant with a $\mathrm{p}$ value $<0.001$

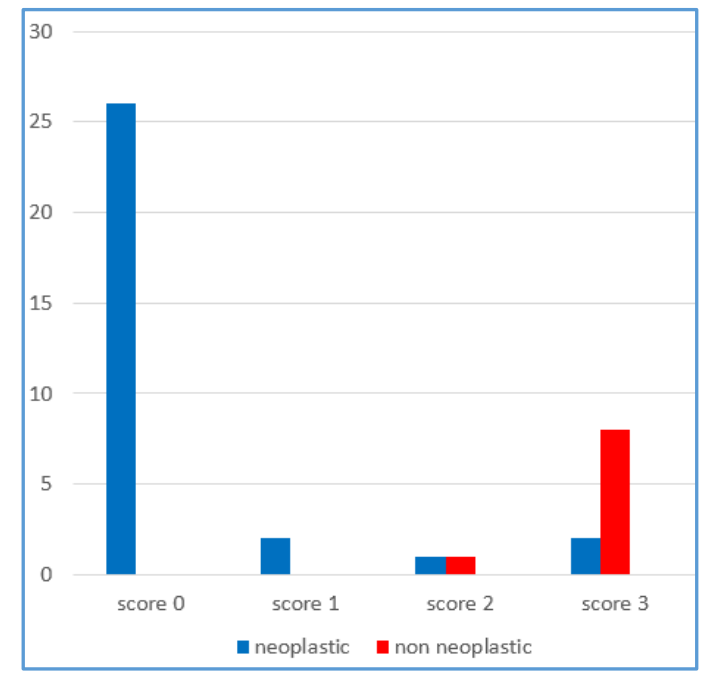

Figure 1:CD56 Expression in Neoplastic Thyroid Lesions of Study Group

\section{CD56 Expression in PTC and its Variants}

The study group consisted of 14 cases of classical PTC, 4 cases of papillary microcarcinoma, 6 cases of FVPTC and 1 cases of diffuse sclerosing variant of PTC. A negative expression of CD 56 with score 0 was shown by thirteen cases $(92.85 \%)$ of classical PTC, all four cases of papillary microcarcinoma (100\%), all six cases of FVPTC (100\%) and a single case of diffuse sclerosing variant (100\%). A score of 1 was shown by a single case of classical PTC (7.1\%)

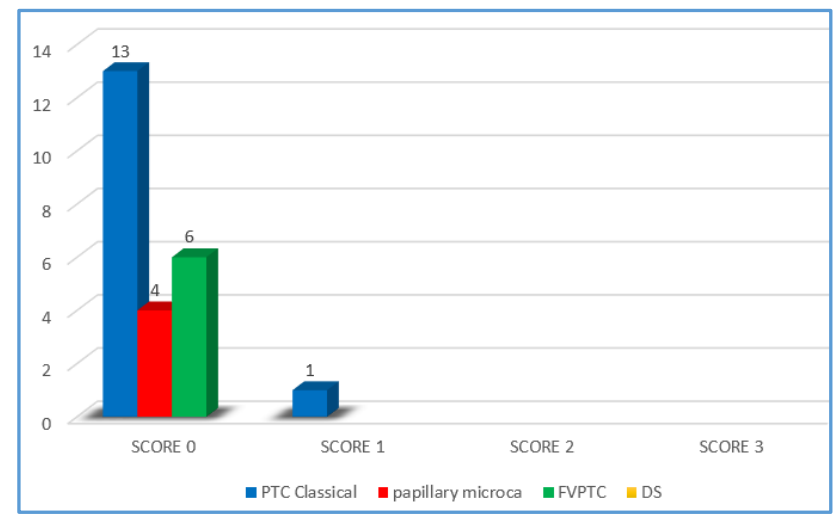

Figure 2: CD56 expression in PTC and its variants

\section{CD56 Expression in Follicular Carcinoma}

Among the 6 cases of $\mathrm{FC}$, one case was FC-WI and 5 cases were FC-MI. Two cases showed a positive expression of CD56 with a score of $3(33.33 \%)$, one case showed a score of 2 $(16.66 \%)$ and one case showed a score of $1(16.66 \%)$. Two cases (33.33\%) showed negative expression of CD56 with score 0 which included the FC-WI.

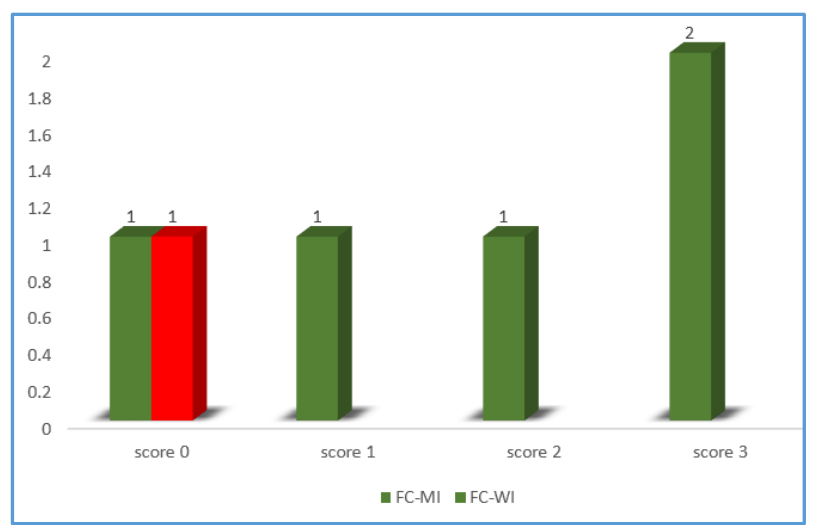

Figure 3: CD56 expression in follicular carcinoma

\section{CD56 Expression in PTC and NON-PTC Lesions}

CD56 showed a negative expression of score 0 in twenty-four $(96 \%)$ cases of PTC and its variants and score 1 in one $(4 \%)$ case. The non-PTC lesions which included FC-MI, FC-WI and cellular nodule showed a score of 0 in 2 cases $(13.3 \%)$ cases, a score of 1 in one case (6.7\%), a score of 2 in two cases $(13.3 \%)$ and a score of 3 in $10(66.7 \%)$ cases. The difference in expression of CD56 between PTC and Non-PTC lesions was found to be statistically significant with a $\mathrm{p}$ value $<0.001$. 


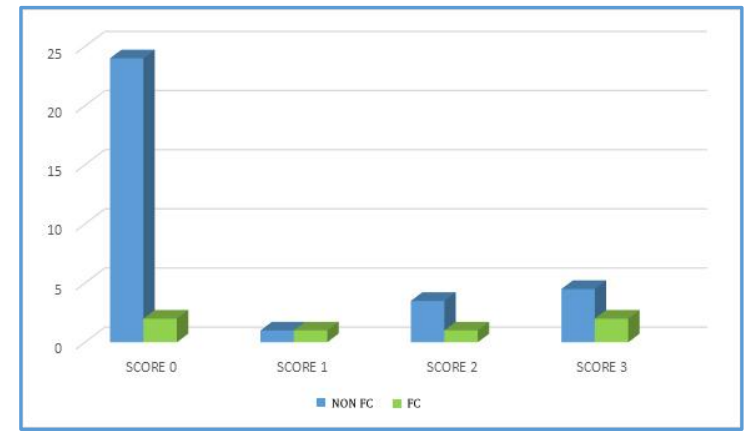

Figure 4: CD56 expression in FC and non FC Lesions

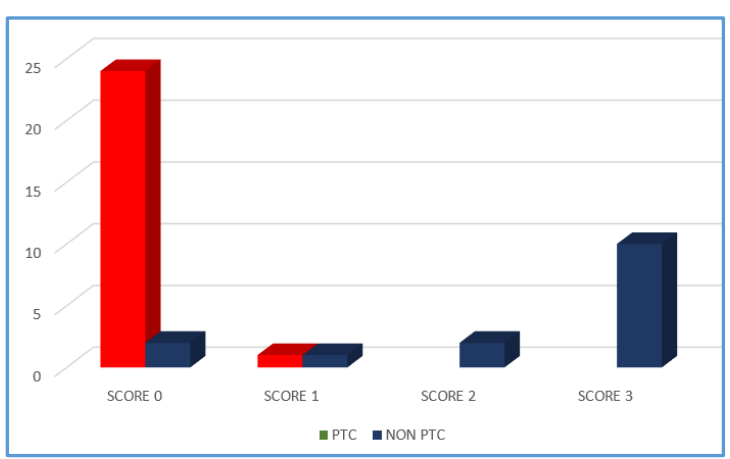

Figure 5: CD56 expression in PTC and NON-PTC lesions

PTC- Classical Variant

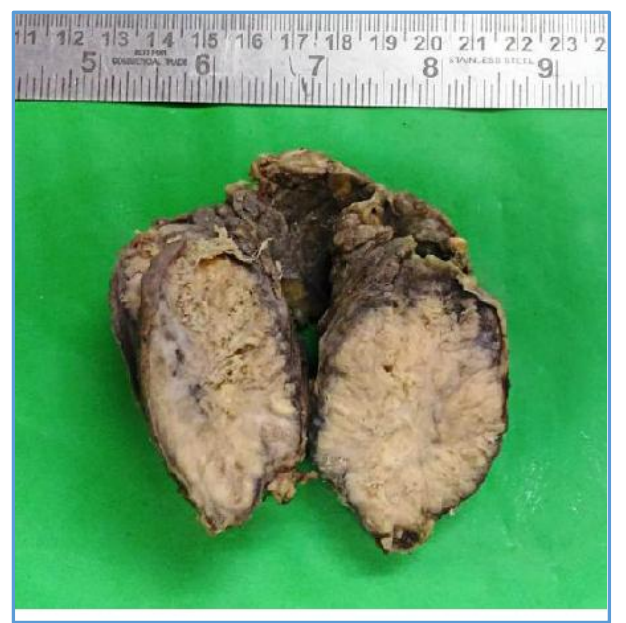

Gross photograph of conventional papillary carcinoma thyroid, cut section is solid, grey white and granular

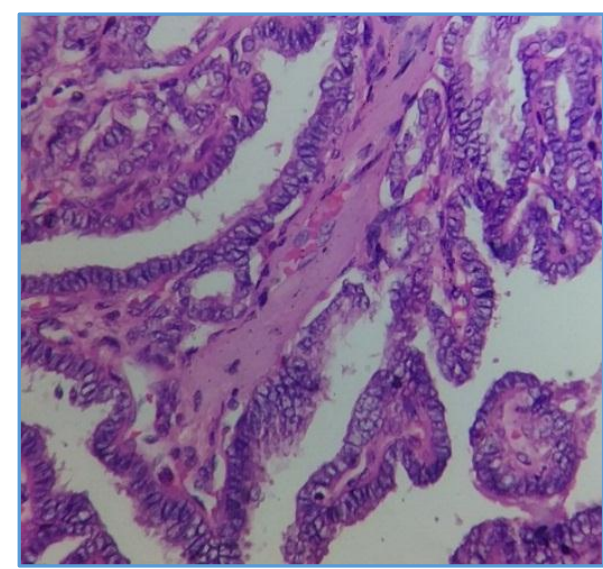

Photomicrograph of conventional PTC, H \& E stain (40x)

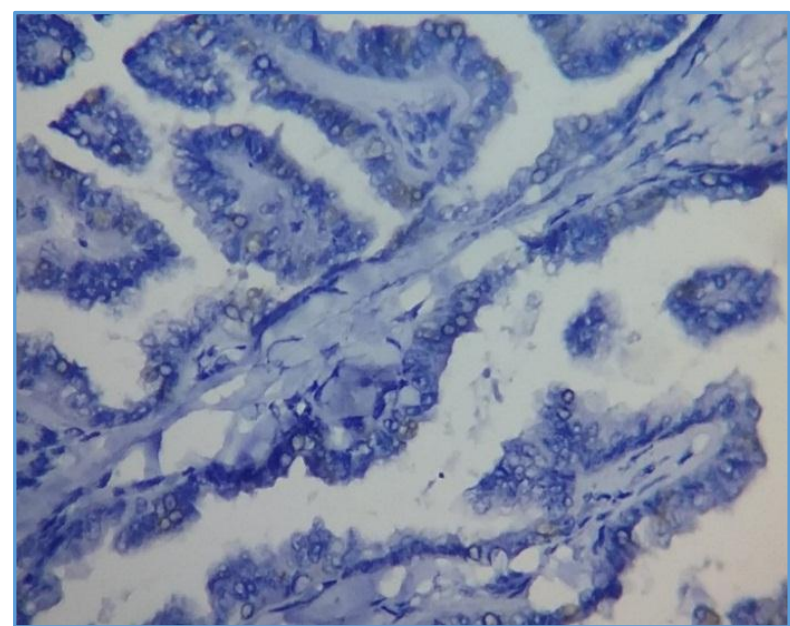

Photomicrograph of IHC -CD56 staining (40x) in classical PTC. Cells shows negative expression of CD56 with no membranous staining

Papillary Microcarcinoma of Thyroid

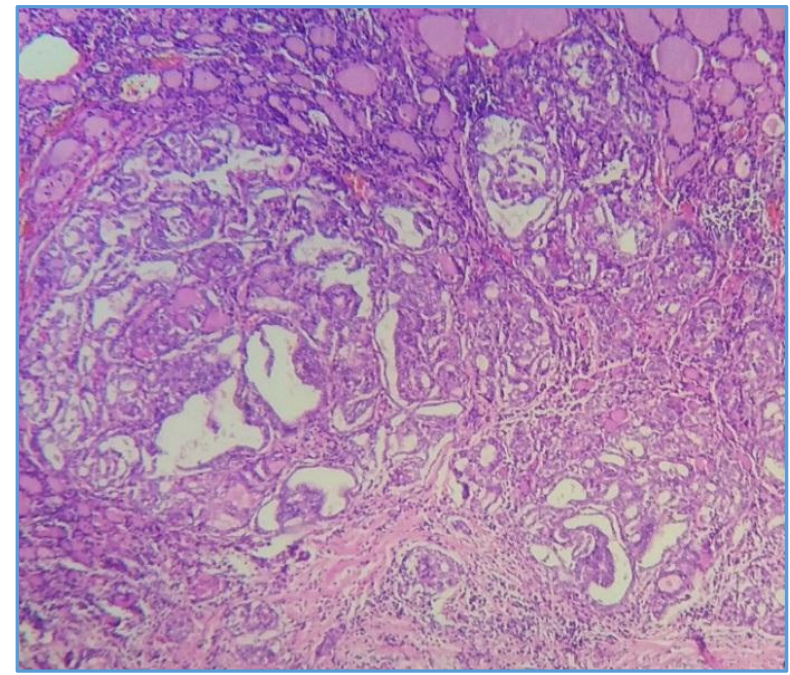

Photomicrograph of papillary microcarcinoma in H\&E stain-(10x)

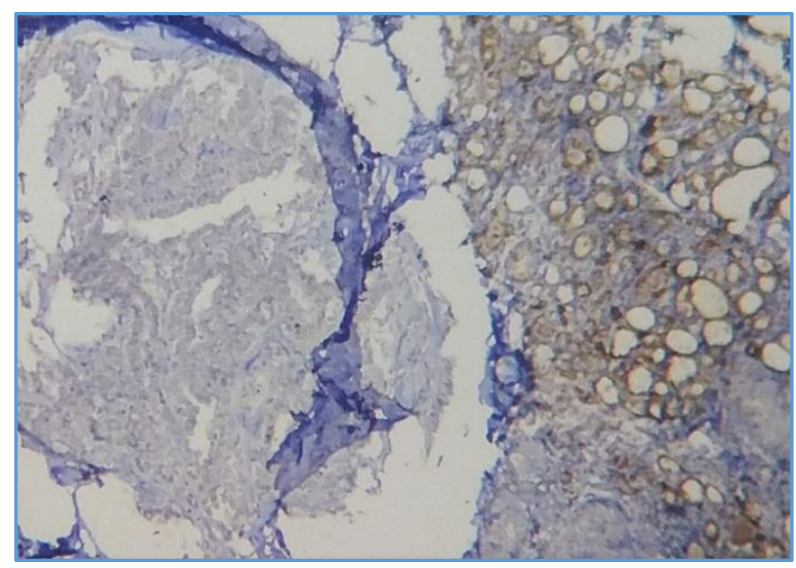

Photomicrograph of CD56 IHC stain in papillary microcarcinoma thyroid (10x)-shows negative expression in papillary microcarcinoma and positive expression in surrounding thyroid 
Follicular Variant of PTC

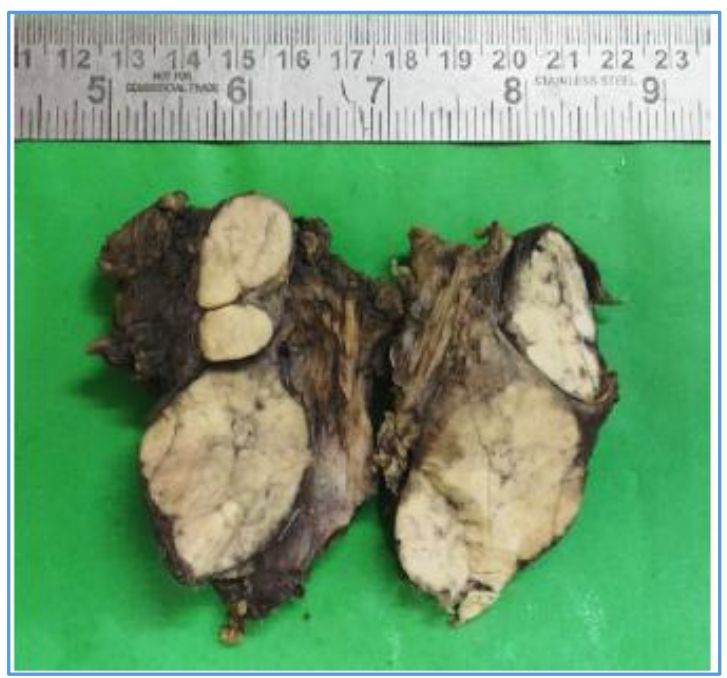

Gross photograph of follicular variant of PTC. Cut section is solid grey white and lobulated

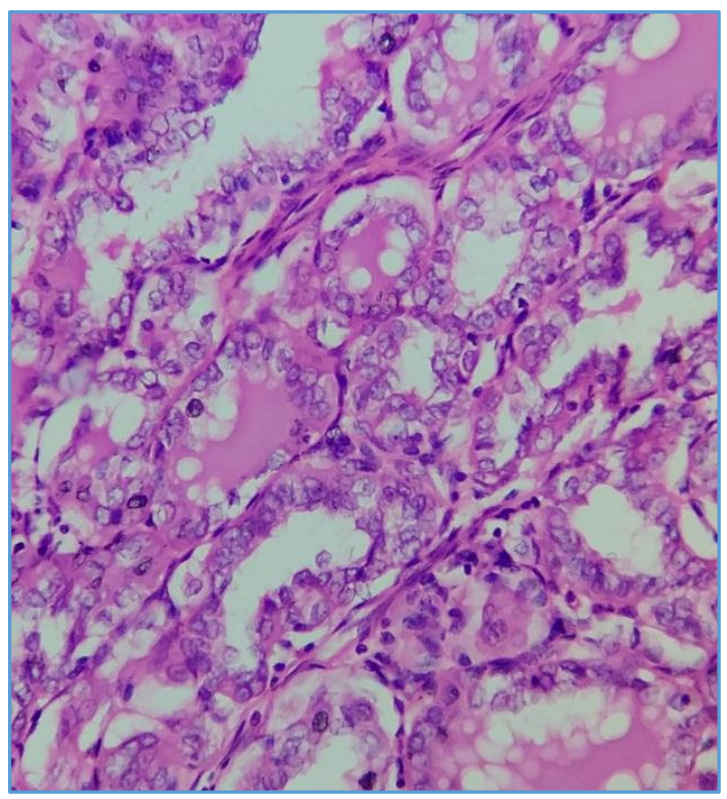

Photomicrograph of follicular variant of PTC- H\& E Stain (40X)

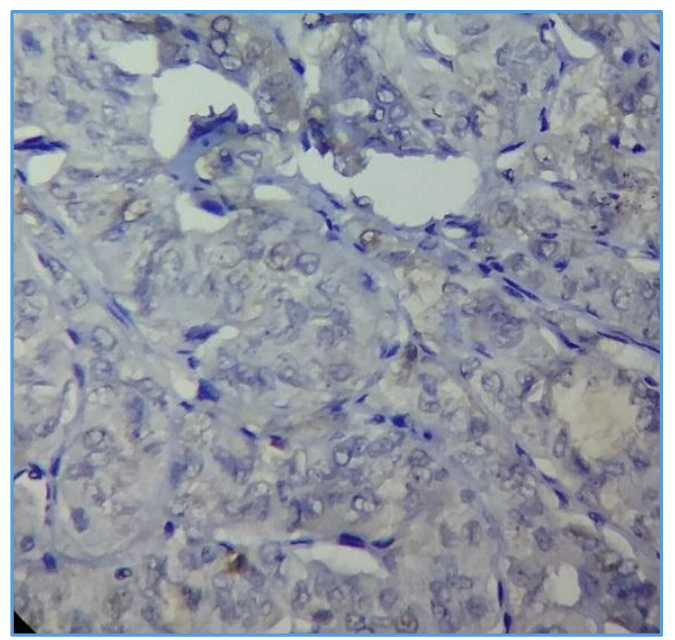

Photomicrograph of IHC-CD56 staining (40x)-shows negative expression with no membranous staining
Diffuse Sclerosing Variant of Thyroid

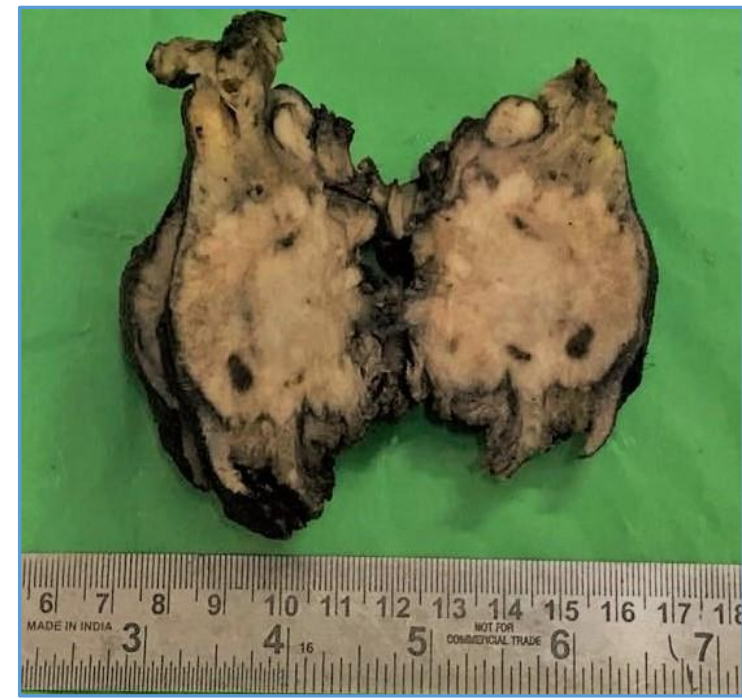

Gross photograph of diffuse sclerosing variant of PTC-cut section is ill-defined grey white lesion

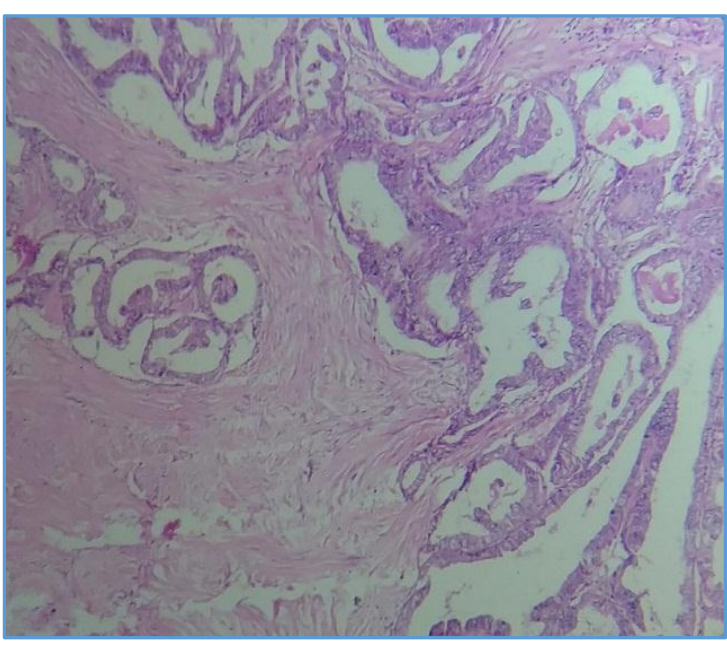

Photomicrograph of Diffuse sclerosing variant of PTC- H\&E stain (40x)

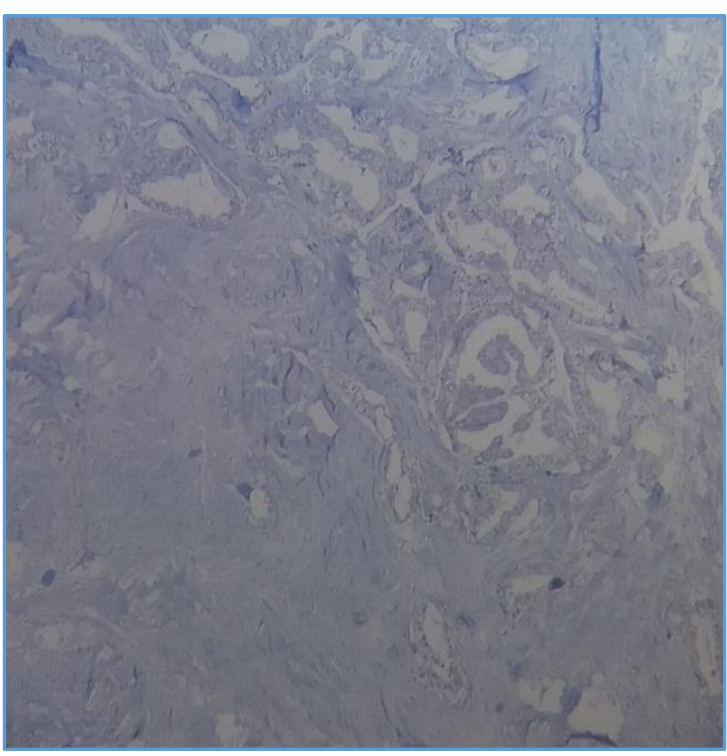

Photomicrograph of IHC staining-CD56 in diffuse sclerosing variant of PTC (40x)-shows negative expression of CD56 -no membranous staining 


\section{Follicular Carcinoma}

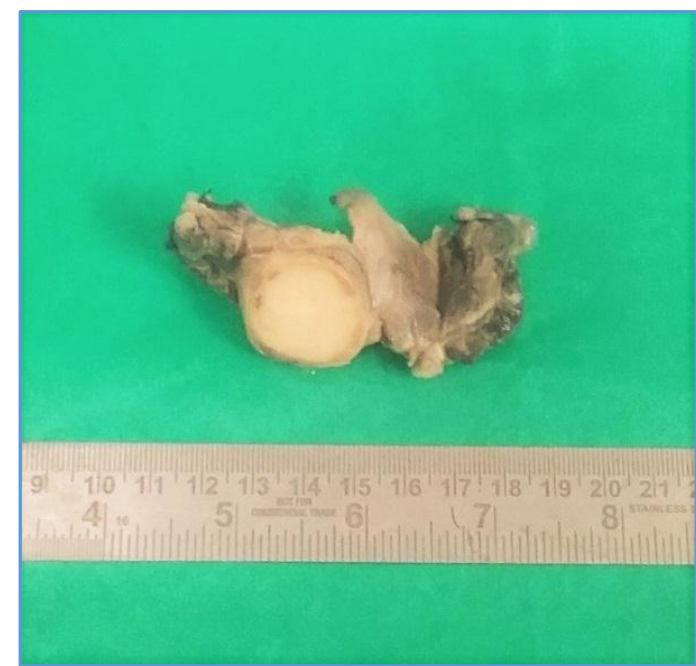

\section{Gross photograph of follicular carcinoma-cut section shows an ill-defined grey white lesion}

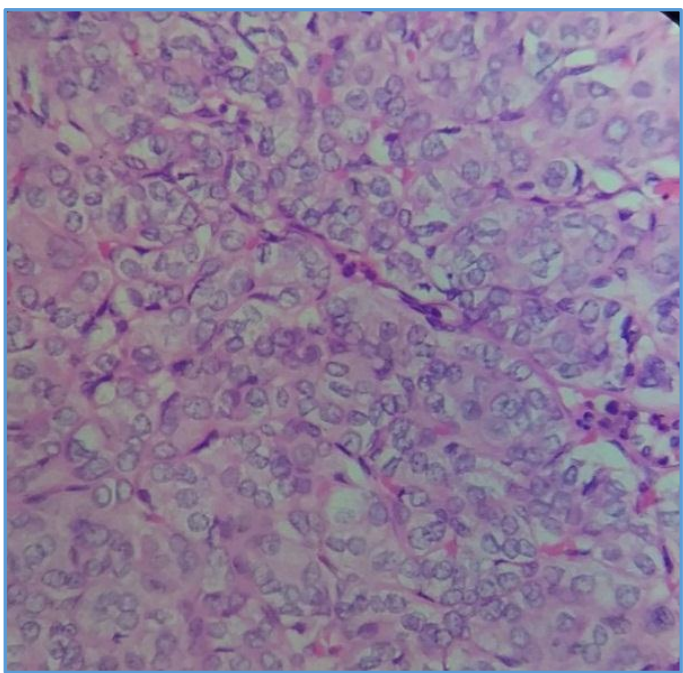

Photomicrograph of follicular carcinoma-40x-H\&E stain

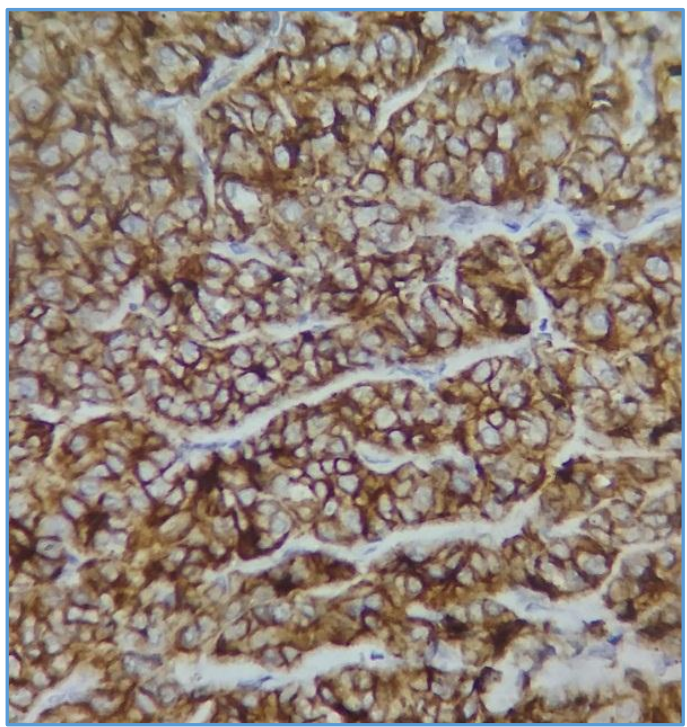

Photomicrograph of CD56 staining in follicular carcinoma-40x-shows positive membranous staining

\section{DISCUSSION}

Follicular thyroid lesions share many morphological features that makes it at times difficult for a pathologist to morphologically distinguish between them. Diagnosis of PTC is based on characteristic nuclear features like clearing, grooving and crowding, however these same features can occur focally in other follicular epithelial lesions like cellular nodule believed to be due to defects in processing in which case the distinction between the two often becomes difficult. Similarly, FVPTC is often indistinguishable from FC as the diagnosis solely depends on nuclear features and evaluation of vascular and capsular invasion. Many IHC markers have been employed to solve these dilemmas but with conflicting results. This study was conducted to evaluate the expression of CD56 in follicular cell derived lesions of thyroid

The present study was conducted on 40 cases of follicular cell derived lesions of thyroid received in the Department of Pathology, Govt. Medical College, Kottayam between May 2016 and October 2017.

The mean age of the study population in this study was $47.25 \pm 16$ years which is comparable with a study conducted by Mokthari et al in 2013 which was $42.42 \pm 17$ years.(1) Similarly in a study conducted by Dunderovic et al in 2015 the mean age was $51 \pm 14$ years. ${ }^{(2)}$

\begin{tabular}{|c|c|c|c|}
\hline Study & $\begin{array}{c}\text { Year of } \\
\text { Study }\end{array}$ & $\begin{array}{c}\text { No. of } \\
\text { Cases }\end{array}$ & Mean Age \\
\hline Mokthari et al(1) & 2013 & 143 & $42.42 \pm 17$ years \\
\hline $\begin{array}{c}\text { Dunderovic et } \\
\text { al(2) }\end{array}$ & 2015 & 201 & $51 \pm 14$ years \\
\hline Present study & 2017 & 40 & $47.25 \pm 16$ years \\
\hline
\end{tabular}

Table 1. Comparison of mean age of study group with other studies

\begin{tabular}{|c|c|c|c|}
\hline Study & Year of Study & No. of Cases & $\begin{array}{c}\text { Female: } \\
\text { Male }\end{array}$ \\
\hline Mokthari et al(1) & 2013 & 143 & $2.9: 1$ \\
\hline $\begin{array}{c}\text { Dunderovic et al } \\
\text { (2) }\end{array}$ & 2015 & 201 & $3.5: 1$ \\
\hline Present study & 2017 & 40 & $3: 1$ \\
\hline \multicolumn{3}{|c|}{ Table 2. Comparison of female:male ratio of study group } \\
with other studies \\
\hline
\end{tabular}

The present study group comprised of 31 neoplastic and 9 non-neoplastic lesions. Neoplastic lesions included PTC ( $\mathrm{n}=$ $25,62.5 \%)$ and FC $(n=6,15 \%)$ and non-neoplastic lesions included cellular nodule $(n=9,22.5 \%)$. Among the 25 cases of PTC, majority were classical PTC lesions $(n=14,56 \%)$. Rest were contributed by papillary microcarcinoma $(n=4,16 \%)$, FVPTC $(n=6,24 \%)$ and diffuse sclerosing variant of PTC $(n=1$, $4 \%)$

The non-neoplastic lesions comprising of cellular nodules showed a positive expression of CD56 with a score 3 in 8 cases $(88.88 \%)$ and a score 2 in one case $(11.12 \%)$. A variable immunostaining of CD56 was observed in cellular nodule with normofollicular and macrofollicular pattern showing more positivity for CD56 in comparison to microfollicular pattern. In a study by W Y Park et al(3) CD56 showed a positive expression in $90.5 \%$ cases of nodular hyperplasia comparable to our study. In a study done by Alshenaway et al(4) $80 \%$ cases of nodular goitre showed a positive expression of CD56 which was comparable with our study. 


\begin{tabular}{|c|c|c|c|c|}
\hline Study & $\begin{array}{c}\text { Year of } \\
\text { Study }\end{array}$ & $\begin{array}{c}\text { No. of } \\
\text { Cases }\end{array}$ & \multicolumn{2}{|c|}{ CD56 expression } \\
\cline { 4 - 5 } & 2009 & 21 & $19(90.5 \%)$ & $2(9.5 \%)$ \\
\hline W Y Park et al(3) & 2014 & 5 & $4(80 \%)$ & $1(20 \%)$ \\
\hline $\begin{array}{c}\text { Alshenaway et } \\
\text { al( }(4)\end{array}$ & $2014)$ & 0 \\
\hline Present study & 2017 & 9 & $9(100 \%)$ & 0 \\
\hline Table 3. Comparison of CD56 expression in nodular \\
hyperplasia with other studies
\end{tabular}

In the present study group CD56 expression was negative (score 0) in $92.85 \%$ cases of classical PTC $(n=14)$. One case of classical PTC showed a positive expression of CD56 with a score of 1.This was comparable to a study by A. Nechifor Boila et al(5) in which a negative expression of CD56 with score 0 was seen in $95.9 \%$ cases of classical PTC. Similarly in a study by Alshenawy et al,(4) classical PTC showed a negative expression of CD56 with a score 0 in $85.71 \%$.

\begin{tabular}{|c|c|c|c|c|}
\hline Study & $\begin{array}{c}\text { Year } \\
\text { of } \\
\text { Study }\end{array}$ & $\begin{array}{c}\text { No. of } \\
\text { Cases }\end{array}$ & Negative & Positive \\
\cline { 4 - 6 } $\begin{array}{c}\text { Alshenawy et } \\
\text { al(4) }\end{array}$ & 2014 & 14 & $12(85.71 \%)$ & $2(14.28 \%)$ \\
\hline $\begin{array}{c}\text { A.Nechifor Boila } \\
\text { et al(5) }\end{array}$ & 2014 & 98 & $92(93.8 \%)$ & $6(6.12 \%)$ \\
\hline Present study & 2017 & 14 & $13(92.85 \%)$ & $1(7.14 \%)$ \\
\hline Table 4. Comparison of CD56 expression in classical PTC \\
with other studies \\
\hline
\end{tabular}

\begin{tabular}{|c|c|c|c|c|}
\hline Study & $\begin{array}{c}\text { Year } \\
\text { of } \\
\text { Study }\end{array}$ & $\begin{array}{c}\text { No. of } \\
\text { Cases }\end{array}$ & Negative & Positive \\
\hline Alshenawy et al( $(4)^{*} 2014$ & 8 & $7(87.5 \%)$ & $1(12.5 \%)$ \\
\hline $\begin{array}{c}\text { A.Nechifor Boila } \\
\text { et al(5) }\end{array}$ & 2014 & 90 & $66(73.3 \%)$ & $24(26.66 \%)$ \\
\hline Present study & 2017 & 6 & $6(100 \%)$ & 0 \\
\hline Table 5. Comparison of CD56 expression in FVPTC with \\
other studies \\
\hline
\end{tabular}

\begin{tabular}{|c|c|c|c|c|}
\hline \multirow{2}{*}{ Study } & Year of & No. of & \multicolumn{2}{|c|}{ CD56 expression } \\
\cline { 3 - 5 } study & cases & Negative & Positive \\
\hline Mi Kyung Shin et & 2011 & 57 & $55(96.49 \%)$ & $2(3.63 \%)$ \\
al(6) & & 4 & $4(100 \%)$ & 0 \\
\hline Present study & 2017 & 4 & 0 \\
\hline Table 6. Comparison of CD56 expression in Papillary \\
microcarcinoma
\end{tabular}

The study group had one case of diffuse sclerosing variant of PTC which showed a negative expression of CD56. In a study by A.Nechifor Boila et al,(5) $80 \%$ cases showed a negative expression of CD56

\begin{tabular}{|c|c|c|c|c|}
\hline \multicolumn{4}{|c|}{} & \multicolumn{2}{c|}{ CD56 expression } \\
\hline Study & $\begin{array}{c}\text { Year of } \\
\text { Study }\end{array}$ & $\begin{array}{c}\text { No of } \\
\text { Cases }\end{array}$ & Negative & Positive \\
\hline $\begin{array}{c}\text { A.Nechifor Boila et } \\
\text { al(5) }\end{array}$ & 2014 & 5 & $4(80 \%)$ & $1(20 \%)$ \\
\hline Present study & 2017 & 1 & $100 \%$ & 0 \\
\hline \multicolumn{3}{|c|}{ Table 7. Comparison of CD56 expression in diffuse } \\
sclerosing variant of PTC \\
\hline
\end{tabular}

In our study FC showed a positive expression of CD56 with score 3 in 2 cases (33.33\%), a score of 2 was seen in one case(16.66\%), one case $(16.66 \%)$ showed a score of 1 , two cases (33.33\%) showed a negative expression of CD56 with score 0 while PTC and its variants showed a negative expression of CD56 with score 0 in $96 \%$ cases. However, the smaller sample size of FC became a limiting factor in its evaluation. In a study by W Y Park et al(3) CD56 showed a positive expression in $82.6 \%(n=23)$ of follicular carcinoma while a negative expression of CD56 with a score 0 was seen in $92.5 \%(n=67)$ of papillary carcinoma.

\begin{tabular}{|c|c|c|c|c|c|c|c|}
\hline \multirow{2}{*}{ Study } & \multirow{2}{*}{$\begin{array}{c}\text { of } \\
\text { of }\end{array}$} & \multicolumn{5}{|c|}{ CD56 Expression } \\
\cline { 3 - 7 } & Study & $\mathrm{n}$ & Negative & Positive & $\mathrm{N}$ & negative & Positive \\
\hline $\begin{array}{c}\text { WY Park } \\
\text { et al(3) }\end{array}$ & 2009 & 67 & 62 & 5 & 23 & 4 & 19 \\
$(92.5 \%)$ & $(7.5 \%)$ & & $(17.4 \%)$ & $(82.6 \%)$ \\
\hline $\begin{array}{c}\text { Present } \\
\text { study }\end{array}$ & 2017 & 25 & $\begin{array}{c}24 \\
(96 \%)\end{array}$ & $\begin{array}{c}1 \\
(4 \%)\end{array}$ & 6 & $\begin{array}{c}2 \\
(33.33 \%)\end{array}$ & $\begin{array}{c}4 \\
66.66 \%)\end{array}$ \\
\hline \multicolumn{7}{|c|}{ Table 8. Comparison of CD56 expression in PTC and FC } \\
\hline
\end{tabular}

A study by Salama et al (7) to study the usefulness of CD56 to differentiate between PTC and benign hyperplasia showed $86.7 \%$ cases of benign hyperplasia with a positive expression of CD56.

\begin{tabular}{|c|c|c|c|c|c|c|c|}
\hline \multirow{2}{*}{ Study } & \multirow{2}{*}{$\begin{array}{c}\text { of } \\
\text { of } \\
\end{array}$} & \multicolumn{5}{|c|}{ CD56 Expression } \\
\cline { 3 - 7 } & Study & $\mathrm{n}$ & Negative & Positive & $\mathrm{N}$ & Negative & Positive \\
\hline $\begin{array}{c}\text { Salama et } \\
\text { al(7) }\end{array}$ & 2016 & 15 & $\begin{array}{c}14 \\
(93.3 \%)\end{array}$ & $\begin{array}{c}1 \\
(6.7 \%)\end{array}$ & 15 & 2 & 13 \\
$(13.3 \%)$ & $(86.7 \%)$ \\
\hline $\begin{array}{c}\text { Present } \\
\text { study }\end{array}$ & 2017 & 25 & $\begin{array}{c}24 \\
(96 \%)\end{array}$ & $\begin{array}{c}1 \\
(4 \%)\end{array}$ & 9 & 0 & $\begin{array}{c}\text { Penign Hyperplasia } \\
(100 \%)\end{array}$ \\
\hline
\end{tabular}

Table 9. Comparison of CD56 expression in PTC and benign hyperplasia

\begin{tabular}{|c|c|c|c|c|c|c|c|}
\hline & Year & \multicolumn{3}{|c|}{ PTC } & \multicolumn{3}{c|}{ NON-PTC } \\
\cline { 3 - 7 } & $\begin{array}{c}\text { of } \\
\text { Study }\end{array}$ & $n$ & Negative & Positive & $n$ & Negative & Positive \\
\hline $\begin{array}{c}\text { Abouhashem } \\
\text { et al(8) }\end{array}$ & 2017 & 33 & $\begin{array}{c}27 \\
(81.8 \%)\end{array}$ & $\begin{array}{c}6 \\
(18.2 \%)\end{array}$ & 47 & $\begin{array}{c}6 \\
(12.7 \%)\end{array}$ & $\begin{array}{c}41 \\
(87.3 \%)\end{array}$ \\
\hline $\begin{array}{c}\text { Present } \\
\text { study }\end{array}$ & 2017 & 25 & $\begin{array}{c}24 \\
(96 \%)\end{array}$ & $\begin{array}{c}1 \\
(4 \%)\end{array}$ & 15 & $\begin{array}{c}2 \\
(13.3 \%)\end{array}$ & $\begin{array}{c}13 \\
(86.7 \%)\end{array}$ \\
\hline
\end{tabular}

Table 10. Comparison of CD56 expression in PTC and NonPTC lesions

\section{CONCLUSION}

CD56 Expression in Follicular Cell Derived Lesions of Thyroid was as follows-

1. CD56 showed a positive expression in $100 \%$ cases of non-neoplastic lesions of thyroid all of which were cellular nodules. Among the neoplastic lesions, a positive expression was seen in $66.66 \%$ cases of $\mathrm{FC}$ and a negative expression of score 0 was seen in $96 \%$ cases of PTC and its variants.

2. Hence based on the findings of the present study CD56 may be considered as a relevant marker of PTC and its variants and is useful in distinguishing PTC and hyperplasia/FC.

\section{REFERENCES}

[1] Mokhtari M, Eftekhari M, Tahririan R. Absent CD56 expression in papillary thyroid carcinoma: a finding of potential diagnostic value in problematic cases of thyroid pathology. J Res Med Sci 2013;18(12):104650 . 


\section{Jemds.com}

[2] Dunđerović D, Lipkovski JM, Boričic I, et al. Defining the value of CD56, CK19, Galectin 3 and HBME-1 in diagnosis of follicular cell derived lesions of thyroid with systematic review of literature. Diagn Pathol 2015;10:196.

[3] Park WY, Jeong SM, Lee JH, et al. Diagnostic value of decreased expression of CD56 protein in papillary carcinoma of the thyroid gland. Basic and Applied Pathology 2009;2(2):63-8.

[4] Alshenawy HA. Utility of immunohistochemical markers in diagnosis of follicular cell derived thyroid lesions. Pathol Oncol Res 2014;20(4):819-28.

[5] Nechifor-Boila A, Catana R, Loghin A, et al. Diagnostic value of HBME-1, CD56, Galectin-3 and Cytokeratin-19 in papillary thyroid carcinomas and thyroid tumors of uncertain malignant potential. Rom J Morphol Embryol 2014;55(1):49-56.

\section{Original Research Article}

[6] Shin MK, Kim JW, Ju YS. CD56 and high molecular weight cytokeratin as diagnostic markers of papillary thyroid carcinoma. Korean J Pathol 2011;45:477-84.

[7] Salama ME, Ibrahim WS. Use of CD56 and cyclin D1 in differentiating thyroid hyperplasia from papillary thyroid carcinoma: an immunohistochemical study. Egypt J Pathol 2016;36:39-42.

[8] Abouhashem NS, Talaat SM. Diagnostic utility of CK19 and CD56 in the differentiation of thyroid papillary carcinoma from its mimics. Pathol Res Pract 2017;213(5):509-17. 